\title{
Sistem Identifikasi Boraks pada Bakso Daging Sapi Berbasis Android Menggunakan Algoritma Naive Bayes Classifier
}

\author{
Sofi Dwi Purwanto, Irwan Budi Santoso
}

\begin{abstract}
The first point to be focused in the fulfillment of the security is in the field of food security. In Indonesia, there are still some phenomena such as the use of borax as an active ingredient chemicals (food additive) in meatballs. It is still a trend poses in the fulfillment of human rights in achieving food security. This study implements the naïve bayes classifier methods as a borax detector on meatball, to perform grayscale and estimate the distribution parameters object features for image data of the training process. While the testing process is also going through a grayscale phase, then the identification process by using the discriminant function and the estimation of distribution parameters. The amount of data used in the study of 840 images. The trial results showed the best results obtained with an accuracy rate of $82.78 \%$ for the image dimension is $3 \times 4$.
\end{abstract}

Keywords- Meatballs, Borax, Feature, Naïve bayes classifier

Abstrak-Poin pertama yang menjadi fokus dalam pemenuhan keamanan adalah keamanan dalam bidang pangan (food security). Di Indonesia, masih terdapat beberapa fenomena seperti penggunaan boraks sebagai zat aktif kimia pada bakso. Hal ini masih menjadi tren yang menjadi hambatan dalam pemenuhan hak manusia dalam mewujudkan keamanan pangan. Penelitian ini mengimplementasikan metode naïve bayes classifiersebagai pendeteksi (detektor) boraks pada bakso daging sapi, dengan melakukan grayscale dan melakukan estimasi parameter distribusi fitur objek untuk data citra proses training. Sedangkan proses testing juga akan melalui tahap grayscale, selanjutnya proses identifikasi dengan menggunakan fungsi diskriminan dan hasil estimasi parameter distribusi. Jumlah data yang digunakan dalam penelitian sebesar 840 citra meliputi 780 bakso yang dibuat secara mandiri dan 60 data diperoleh dari hasil survey dilapangan. Hasil uji coba menunjukkan bahwa

Manuscript received February 22, 20017. This work was supported in part by Informatics Engineering Department of Maulana Malik Ibrahim Islamic State University.

Sofi Dwi Purwanto is with the Informatic Engineering Departement of Maulana Malik Ibrahim Islamic State University, Malang,Indonesia; email dwihayyana@gmail.com

Irwan Budi Santosois the Informatic Engineering Departement of Maulana Malik Ibrahim Islamic State University, Malang, Indonesia; email irwan.budi331177@ gmail.com)

T. C. Author is is the Informatic Engineering Departement of Maulana Malik Ibrahim Islamic State University, Malang, Indonesia (corresponding author provide phone 0341-000000; email author@uin-malang.ac..id hasil terbaik diperoleh dengan tingkat akurasi sebesar $82.78 \%$ untuk dimensi citra $3 \times 4$.

Keywords - Bakso, Boraks, Fitur, Naive bayes classifier

\section{PENDAhUluan}

Security (keamanan) adalah sesuatu yang menjadi hak bagi setiap manusia dalam menjalani kehidupan, dan hal ini akan menjadi sesuatu yang langka apabila tidak didukung oleh manusia lainnya dan sistem yang bersahabat. Dalam Human Development Report yang dipublikasikan oleh United Nations Development Program, human security (keamanan manusia) telah didefinisikan sebagai suatu konsep keamanan dengan tujuh komponen utama, dan dari ketujuh komponen tersebut terdapat kurang lebih tiga komponen yang setidaknya patut diperoleh oleh setiap manusia, yakni food security (keamanan pangan), political security (HAM), dan individual security (kekerasan dan ancaman). Dalam pemenuhan ketiga hak keamanan yang seharusnya didapat oleh setiap manusia tersebut, seringkali ada hal yang membuat hal-hal tersebut belum dapat dipenuhi. Seperti masih sulitnya untuk mendapatkan keamanan dalam bidang pangan dan perlindungan hukum [1].

Poin pertama yang menjadi fokus dalam pemenuhan keamanan adalah keamanan dalam bidang pangan (food security). Di Indonesia,masih terdapat beberapa fenomena seperti penggunaan boraks sebagai zat aktif kimia pada makanan. Hal ini masih menjadi tren yang menjadi hambatan dalam pemenuhan hak manusia dalam mewujudkan keamanan pangan.

Bakso merupakan produk dari daging, baik daging sapi, ayam ikan maupun udang.Pada proses pengolah makanan seperti halnya bakso sering ditambahkan bahan tambahan makanan (BTM) atau yang biasa disebut dengan zat aktif kimia (food additive). Selain bahan pengenyal alami dan sintesis, ada juga produsen bakso yang masih menggunakan bahan pengenyal yang dilarang seperti boraks. Sebagaimana yang telah diberitakan dalam beberapa media terkait persoalan ini seperti di kantor wali kota Jakarta Utara[2], Mall Kelapa Gading [3], dan di Tangerang [4].

Pemerintah sudah mengatur standar keamanan pangan yang layak seperti halnya larangan penggunaan boraks pada makanan. Misalnya SK Kementerian 
Kesehatan RI No. 722/Menkes/Per/IX/1988 yang berisi tentang pelarangan penggunaan boraks, kemudian juga tidak termasuknya boraks ke dalam Peraturan Menteri Kesehatan RI Nomor 235/Men-Kes/Per/VI/79 tentang bahan tambahan makanan yang diperbolehkan, lampiran Peraturan Menteri Kesehatan RI tanggal 19 Juni 1979 No. 235/MenKes/Per/VI/'79, Peraturan SK Menteri Kesehatan RI Nomor 733/Menkes/Per/IX/1988 yang keduanya menyatakan bahwa boraks masuk dalam bahan tambahan makanan yang dilarang dan pemerintah melarang penggunaan boraks pada makanan melalui Permenkes RI No.1168/Menkes/Per/X/1999 tentang bahan makanan tambahan [14].

Beberapa penelitian laboratorium dalam mengidentifikasi kandungan boraks pada bakso telah banyak dilakukan, diantaranya oleh Junianto [5] dan Warni [6] dengan menggunakan spektrofotometri, Tubagus dkk [7] yang dilakukan di Kota Manado. Kajian kemanan pangan bakso juga dilakukan Fauziah [8] di lingkungan Universitas Jember yang ditinjau dari kandungan boraks, formalin, dan TPC.

Penelitian ini mengimplementasikan algoritma naïve bayes classifier pada aplikasi pendeteksi boraks pada bakso daging sapi. Algoritma tersebut dipilih sebagai metode pendeteksi karena sangat cocok untuk objek image dalam bentuk textur, terbebas dari kasus singularitas serta mudah untuk diimplementasikan. Dan dalam kasus penelitian ini data yang akan diambil adalah berupa image dalam bentuk textur. Penelitian yang dilakukan ini merupakan salah satu langkah pengembangan ilmu Teknik Informatika dalam mengidentifikasi boraks untuk mewujudkan keamanan pangan.

\section{NAIVE BAYES ClassifiER}

\section{A. Teorema Naive Bayes}

Bila diketahui $\omega_{j}$ adalah fitur kelas $j$, dan $x$ adalah fitur objek (patternx), maka probabilitas $\omega_{j}$ bila diketahui $x$ dapat dirumuskan dalam persamaan $[9,10]$ :

(1)

$$
p\left(\omega_{j} \mid x\right)=\frac{p\left(\omega_{j}\right) p\left(x \mid \omega_{j}\right)}{p(x)}
$$

nilai $p\left(\omega_{j} \mid x\right)$ equivalen dengan nilai $\log \left(p\left(\omega_{j} \mid x\right)\right)$, sehingga:

$\log \left(p\left(\omega_{j} \mid x\right)\right)=\log \left(p\left(x \mid \omega_{j}\right)\right)+\log \left(p\left(\omega_{j}\right)\right)-\log (p(x))$

\section{B. Singularitas Nä̈ve Bayes Terhadap Gaussian Classifier}

Naïve bayes dapat diasumsikan kedalam model khusus $p(x \mid \theta)$,selanjutnya metode naïve bayes mengestimasi populasi terhadap parameterdistribusi $\theta=(\mu, \Sigma)$ untuk model distribusi Multivariate Normal (Gaussian). Salah satu dari pendekatan paling sederhana untuk menghindari nilai parameter matrik covariance tunggal adalah dengan menggunakan matrik covariance diagonal. Berdasarkan hal tersebut dapat diasumsikan bahwa setiap fitur bersifat independen sehingga diperoleh persamaan [11]:

$$
p\left(x \mid \omega_{j}\right)=\prod_{l=1}^{d} N\left(x_{1} ; \hat{\mu}_{j l}, \hat{\sigma}_{j, l}^{2}\right)
$$

Dimana $\hat{\mu}_{j l}$ merupakan komponen ke- $l$ dari $\hat{\mu}_{j}$ (komponen ke-l berdasarkan mean data sampel dari kelas $\left.\omega_{j}\right), \hat{\sigma}_{j, l}^{2}$ merupakan elemen diagonal ke-l dari $\Sigma_{j}$ (komponen ke- $l$ berdasarkan varian data sampel dari kelas $\left.\omega_{j}\right)$ dan $N\left(x, \mu, \sigma^{2}\right)$ merupakan probability density function dari model distribusi Univariate Normal (Gaussian) dengan mean $\mu$ dan varian $\sigma^{2}$. Teorema tersebut dapat direpsentasikan kedalam fungsi diskriminan, sehingga dengan menggunakan probabilitas bersyarat $x$ terhadap $\omega_{j}$ jika $g_{i}>g_{j}$, untuk semua $j \neq i$ didapatkan fungsi diskriminan [11]sebagai berikut:

$$
\begin{array}{r}
g_{j}(x)= \\
\log \left(p\left(\omega_{j}\right)\right)-\sum_{l=1}^{d} \log \left(\hat{\sigma}_{j, l}\right)-\frac{1}{2} \sum_{l=1}^{d} \frac{\left(x_{l}-\widehat{\mu}_{j l}\right)^{2}}{\widehat{\sigma}_{j, l}^{2}}(4)
\end{array}
$$

Dengan $p\left(\omega_{j}\right)=n_{j} / \sum_{i=1}^{c} n_{i}$

Berdasarkan persamaan 4, maka aturan untuk mengklasifikasikan pattern $x$ adalah:

$$
\hat{C}=\arg \max \left(g_{j}(x)\right), j=1, \ldots, C
$$

Dimana $\hat{C}$ adalah kelas objek terpilih [10].

\section{METODE PENELITIAN}

\section{A. Kerangka Kerja Sistem}

Desain sistem yang akan dibangun adalah seperti pada gambar 1. Sistem meliputi bagian training dan testing dimana pada kedua bagian tersebut melewati 2 proses yang sama, yakni preproses dan ekstraksi fitur untuk mendapatkan ciri objek [12]. Selanjutnya pada proses training akan dilakukan estimasi terhadap parameter distribusi fitur objek. Hasil proses ini akan disimpan untuk digunakan pada proses testing berdasarkan fungsi diskriminan.

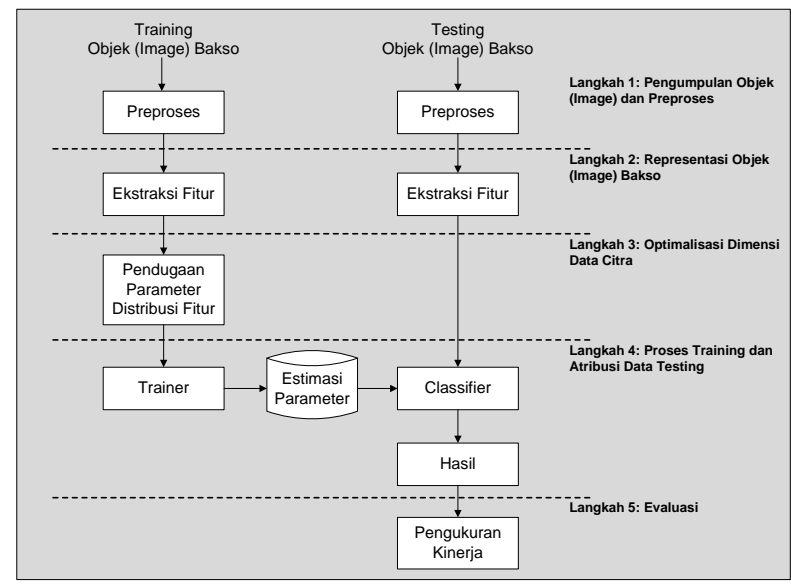

Gambar 1. Desain system

\section{B. Instrumen Pengambilan Data}

Instrumen pengambilan data yang digunakan dalam penelitian didesain khusus (dibuat sendiri) dengan menyesuaikan kemampuan kamera yang akan digunakan untuk mengambil citra bakso daging sapi. 


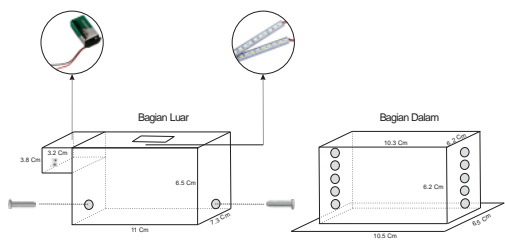

Gambar 2. Desain alat khusus pengambilan data

Alat tersebut berbentuk kubus yang bersifat kedap cahaya, pada bagian atas terdapat tempat untuk kamera yang bersifat permanen sehingga saat pengambilan gambar kamera tidak bergeser. Alat ini juga dapat mengatur tinggi antara lensa kamera dengan objek yang akan diambil gambarnya agar fokus kamera dapat bekerja dengan optimal. Selain itu alat juga dilengkapi dengan LED agar bakso yang terdapat didalamnya dapat memperoleh cahaya.

\section{Model Fitur}

1) Grayscale: Citra grayscale digunakan untuk merepresentasikan fitur intensitas cahaya pada bakso daging sapi. Proses ini akan mengubah nilai matrik masing-masing $R, G$ dan Bkedalam nilai Gray, sehingga dapat dituliskan menjadi[13]:

$$
\text { Gray }=(R \times 0.299)+(G \times 0.587)+(B \times 0.114)
$$

2) Estimasi Parameter:Fitur objek diasumsikan mengikuti distribusi Univariate Normal (Gaussian) dengan parameter model dari mean dan varian. Sehingga didapatkan parameter mean distribusi sebagai berikut:

$$
\hat{\mu}=\frac{1}{2} \sum_{i=1}^{n} x_{i}(7)
$$

Serta hasil pendugaan parameter varian adalah[11]:

$$
\hat{\sigma}^{2}=\frac{1}{n-1} \sum_{i=1}^{n}\left(x_{i}-\hat{\mu}\right)^{2}
$$

\section{ANALISIS EMPIRIS}

\section{A. Deskripsi Data}

Data yang akan digunakan dalam penelitian ini adalah data primer yang diperoleh dari pengolahan bakso daging sapi oleh peneliti. Jumlah keseluruhan data yang akan digunakan dalam penelitian sebesar 840 citra bakso daging sapi meliputi 780 data bakso yang dibuat secara mandiri dan 60 bakso diperoleh dari hasil survey dilapangan. Penelitian ini juga menggunakan data sekunder yang diperoleh dari survey yang dilakukan dengan mengambil sampel bakso sapi secara acak di 3 kecamatan di kota Malang, yakni Kecamatan Lowokwaru, Kecamatan Klojen, dan Kecamatan Blimbing. Sedangkan perolehan dataset untuk bakso yang dibuat secara mandiri yang akan digunakan dalam penelitian melalui beberapa tahapan seperti yang tampak pada gambar 3 .

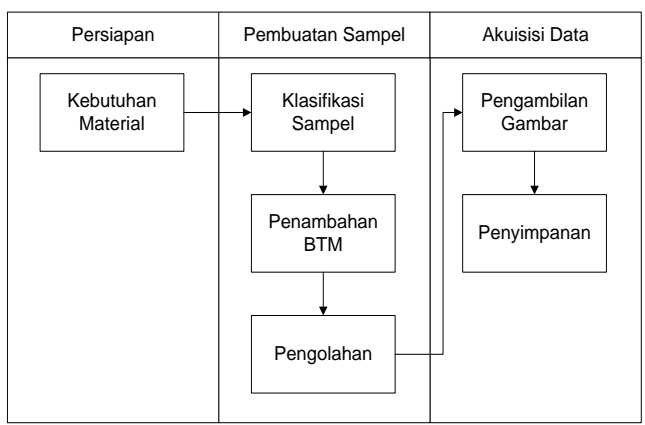

Gambar 3. Prosedur pengumpulan data mandiri

\section{B. Skenario Uji Coba}

Dalam penelitian sistem identifikasi boraks pada bakso berbasis android dengan menggunakan algoritma naive bayes classifier, scenario uji coba yang dilakukan ada 2 yaitu pertama, pengambilan data image bakso boraks dan tidak mengandung boraks dengan menggunakan alat khusus buatan sendiri seperti pada Gambar 2. Kedua pengambilan data image bakso boraks dan tidak mengandung boraks tanpa alat khusus atau menggunakan kamera handphone android min 5 mega pixel. Data yang diambil dari kedua skenario tersebut masing-masing meliputi data untuk training dan data untuk testing. Setelah mendapatkan data tersebut dilakukan training terhadap masing-masing baik menggunakan alat ataupun tanpa alat dan dipilih hasil terbaik. Selanjutnya dari hasil training terbaik tersebut, digunakan untuk melakukan testing baik data yang diambil menggunakan alat, tanpa alat ataupun data survey.

\section{Hasil Training}

Hasil proses training akan menunjukkan pengaruh perubahan dimensi citra data training, prosentase kesalahan, dan akurasi yang dihasilkan oleh sistem. Dari 240 data yang ditraining untuk masing-masing kelas, diperoleh hasil yang berbeda-beda. Untuk masingmasing variasi terhadap dimensi citra data training bakso daging sapi, berikut disajikan dalam tabel I hasil proses training yang telah dilakukan berdasarkan model pengambilan data.

Tabel I Hasil Training

\begin{tabular}{|c|c|c|c|c|}
\hline \multirow{2}{*}{ Dimensi } & \multicolumn{2}{|c|}{ Menggunakan Alat } & \multicolumn{2}{c|}{ Tanpa Alat } \\
\cline { 2 - 5 } & Error (\%) & Akurasi (\%) & Error(\%) & Akurasi(\%) \\
\hline $2 \times 3$ & 6.25 & 93.75 & 32.91 & 67.08 \\
\hline $3 \times 2$ & 8.75 & 91.25 & 34.58 & 65.41 \\
\hline $2 \times 4$ & 9.16 & 90.83 & 32.91 & 67.08 \\
\hline $4 \times 2$ & 8.75 & 91.25 & 34.58 & 65.41 \\
\hline $2 \times 5$ & 5.83 & 94.16 & 32.91 & 67.08 \\
\hline $5 \times 2$ & 7.50 & 92.50 & 34.58 & 65.41 \\
\hline $3 \times 4$ & 5.83 & 94.16 & 34.16 & 65.83 \\
\hline $4 \times 3$ & 7.50 & 92.50 & 34.16 & 65.83 \\
\hline $3 \times 5$ & 5.83 & 94.16 & 34.16 & 65.83 \\
\hline $5 \times 3$ & 7.50 & 92.50 & 32.91 & 67.08 \\
\hline $2 \times 2$ & 8.33 & 91.66 & 33.75 & 66.25 \\
\hline $3 \times 3$ & 10.41 & 89.58 & 32.50 & 67.50 \\
\hline $4 \times 4$ & 7.50 & 92.50 & 33.75 & 66.25 \\
\hline $5 \times 5$ & 7.50 & 92.50 & 33.33 & 66.66 \\
\hline $6 \times 6$ & 7.50 & 92.50 & 33.75 & 66.25 \\
\hline $7 \times 7$ & 5.83 & 94.16 & 33.33 & 66.66 \\
\hline $8 \times 8$ & 5.83 & 94.16 & 33.33 & 66.66 \\
\hline $9 \times 9$ & 5.83 & 94.16 & 33.33 & 66.66 \\
\hline $10 \times 10$ & 5.83 & 94.16 & 33.33 & 66.66 \\
\hline $11 \times 11$ & 5.83 & 94.16 & 33.33 & 66.66 \\
\hline
\end{tabular}


Berdasarkan Tabel I didapatkan bahwa dimensi citra data training yang paling optimal (data diambil alat khusus) pada ukuran 3 x 4 dengan tingkat akurasi sebesar $94.16 \%$, sedangkan untuk pengambilan data tanpa menggunakan alat khusus (dengan kamera handphone) diperoleh hasil paling optimal pada dimensi 3 x 3 dengan akurasi sebesar $67.5 \%$. Berdasarkan hasil training tersebut, maka data estimasi parameter yang akan digunakan untuk proses pengujian menggunakan data citra dengan ukuran $3 \times 4$ untuk pengambilan data dengan menggunakan alat khusus dan dengan ukuran 3 $\mathrm{x} 3$ untuk pengambilan data dengan tanpa menggunakan alat khusus (dengan kamera handphone).

\section{Hasil Testing}

Testing dilakukan dengan membandingkan hasil 180 bakso yang didasarkan pada proses pengolahan untuk pembuatan secara mandiri dan juga berdasarkan pada hasil uji test kit boraks untuk bakso yang diperoleh dari hasil survey dilapangan. Selanjutnya akan dibandingkan untuk kemudian dihitung besar kesalahan dan tingkat akurasi yang diperoleh. Hasil identifikasi sistem berdasarkan variasi ditunjukkan oleh tabel II berikut.

Tabel II Hasil Testing

\begin{tabular}{|l|c|c|c|c|}
\hline \multirow{2}{*}{ Uraian } & \multicolumn{2}{|c|}{ Menggunakan Alat } & \multicolumn{2}{c|}{ Tanpa Alat } \\
\cline { 2 - 5 } & Error(\%) & Akurasi(\%) & Error(\%) & Akurasi(\%) \\
\hline $\begin{array}{l}\text { Tidak } \begin{array}{l}\text { Mengandung } \\
\text { Boraks }\end{array} \\
\text { Kandungan } \\
\text { Boraks 0.5\% }\end{array}$ & 3.33 & 73.33 & 23.33 & 76.66 \\
\hline $\begin{array}{l}\text { Kandungan } \\
\text { Boraks 1\% }\end{array}$ & 13.33 & 86.66 & 3.33 & 96.66 \\
\hline $\begin{array}{l}\text { Kandungan } \\
\text { Boraks 3\% }\end{array}$ & 10 & 90 & 36.66 & 63.33 \\
\hline $\begin{array}{l}\text { Kandungan } \\
\text { Boraks 5\% }\end{array}$ & 0 & 100 & 6.66 & 93.33 \\
\hline $\begin{array}{l}\text { Total } \\
\text { Mengandung } \\
\text { Boraks }\end{array}$ & 6.66 & 93.33 & 20 & 80 \\
\hline Hasil Survey & 50 & 50 & 86.66 & 13.33 \\
\hline Rata-Rata & $\mathbf{1 7 . 2 2}$ & $\mathbf{8 2 . 7 7}$ & $\mathbf{3 1 . 6 6}$ & $\mathbf{6 8 . 3 3}$ \\
\hline
\end{tabular}

\section{E. Analisis Hasil Kerja Sistem}

Proses testing dilakukan sebanyak 12 percobaan dengan 2 model pengambilan dan data yang berbedabeda. Hasil proses testing menunjukkan bahwa secara umum data dengan menggunakan alat menghasilkan tingkat akurasi yang lebih tinggi jika dibandingkan dengan pengambilan data dengan tanpa menggunakan alat. Tingkat akurasi dapat diketahui dengan membandingan hasil yang diperoleh aplikasi dengan data real yang telah diambil oleh peneliti. Sedangkan untuk pengambilan data survey dilapangan dilakukan pengujian laboratorium terlebih dahulu dengan menggunakan reagent atau test kit boraks untuk mengetahui kandungan boraks yang terdapat dalam bakso daging sapi. Hasil keseluruhan proses testing dapat disajikan dalam gambar 4 .

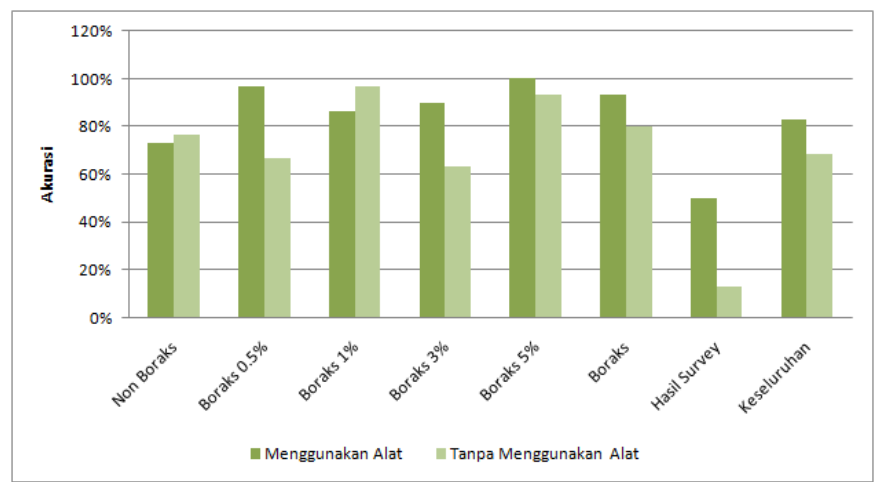

Gambar 4. Grafik hasil testing

secara keseluruhan pengambilan data dengan menggunakan alat memiliki tingkat akurasi yang lebih tinggi, yaitu sebesar $82.77 \%$ dengan jumlah data yang diidentifikasi secara benar oleh aplikasi adalah sebanyak 149 dari 180 data yang digunakan. Sedangkan untuk hasil yang diperoleh dengan pengambilan data tanpa menggunakan alat diperoleh akurasi sebesar $68.33 \%$. ini menunjukkan bahwa secara keseluruhan aplikasi dapat mengenali dengan baik terhadap data yang diambil dengan menggunakan alat. Sedangkan apabila dilihat tingkat akurasi untuk masing-masing perlakuan akan diperoleh hasil yang berbeda-beda. Data yang diperoleh dari survey menunjukkan tingkat akurasi untuk pengambilan data dengan menggunakan alat juga lebih baik dengan prosentase tingkat akurasi sebesar $50 \%$. Kemudian untuk bakso daging sapi yang memiliki kandungan boraks juga menghasilkan tingkat akurasi yang berbeda dengan hasil yang lebih baik untuk pengambilan data dengan menggunakan alat, yakni sebesar $93.33 \%$ sedangkan untuk pengambilan data dengan tanpa menggunakan alat menghasilkan tingkat akurasi sebesar $80 \%$. Adapun akurasi yang diperoleh untuk bakso yang tidak memiliki kandungan boraks adalah sebesar $73.33 \%$ untuk pengambilan data dengan menggunakan alat. Sedangkan pengambilan data dengan tanpa menggunakan alat diperoleh tingkat akurasi yang lebih baik, yakni $76.66 \%$.

Adapun kekurangan sistem, antara lain metode nä̈ve bayes classifier merupakan sistem yang hanya dapat berfungsi sebagai alat bantu. Oleh sebab itu, didalam pengambilan keputusan masih terpengaruh terhadap faktor-faktor pendukung atau kebijakan-kebijakan lain. Selain itu ouput aplikasi dalam mengidentifikasi bakso daging sapi belum sepenuhnya sama persis dengan data real maupun data hasil survey yang telah diuji dengan menggunakan reagent atau test kit boraks. Hal ini disebabkan karena proses pengambilan data citra masih memiliki beberapa kekurangan seperti adanya beberapa data yang tidak fokus, permukaan bakso yang berbeda satu sama lain, adanya pengaruh intensitas cahaya dan kondisi cuaca untuk pengambilan data dengan tanpa menggunakan alat serta adanya perbedaan bahan dan cara pengolahan maupun perlakuan untuk data yang diperoleh dari hasil survey di lapangan. 


\section{KESIMPULAN}

Berdasarkan hasil penelitian dan pembahasan tentang implementasi metode nä̈ve bayes classifier dalam mengidentifikasi kandungan boraks pada citra bakso daging sapi dapat ditarik kesimpulan bahwa hasil yang diperoleh pada training data dengan menggunakan alat didapat tingkat akurasi terbaik adalah sebesar $94.16 \%$ dengan resize sebesar 3x4, 7x7, 8x8, 9x9, 10x10, 11x11. Sedangkan training untuk pengambilan data dengan tanpa menggunakan alat diperoleh akurasi paling optimal sebesar $67.5 \%$ dengan dimensi citra $3 \times 3$. Hasil uji coba data testing citra bakso daging sapi dengan menggunakan alat diperoleh tingkat akurasi sebesar $82.77 \%$ sedangkan untuk pengambilan data dengan tanpa menggunakan alat diperoleh tingkat akurasi $68.33 \%$. Data yang diperoleh melalui hasil survey dilapangan diambil dari kecamatan klojen, kecamatan lowokwaru, dan kecamatan blimbing. Tingkat akurasi terbaik diperoleh melalui data yang diambil dengan menggunakan alat yakni sebesar 50\%. Kurang optimalnya tingkat akurasi disebabkan karena beberapa faktor seperti permukaan bakso yang berbeda satu sama lain, adanya pengaruh intensitas cahaya, kondisi cuaca serta adanya perbedaan bahan, cara pengolahan hingga perlakuan masing-masing pedagang.

\section{REFERENSI}

[1] Laporan Panel Tingkat Tinggi Para Tokoh Terkemuka tentang Agenda Pembangunan Pasca-2015, United Nations Publications, 2013.
[2] Kompas. (2015) BPOM Sita Makanan Mengandung Boraks dari Kantor Walikota Jakarta Utara. [Online]. Tersedia: http://megapolitan.kompas.com

[3] Kompas. (2015) Menu di Mal Kelapa Gading Terbukti Mengandung Boraks. [Online]. Tersedia: http://megapolitan.kompas.com

[4] Vivanews. (2015) Hati - Hati, Makanan Mengandung Boraks Beredar di Tangerang. [Online]. Tersedia: http://m.news.viva.co.id

[5] J. Choirul, "Analisis Boraks pada Bakso Daging Sapi A dan B yang di Jual di Daerah Kenjeran Surabaya Menggunakan Spektrofotometri," Calyptra, vol. 2, pp. 1-10, 2013.

[6] S. A. Warni, "Analisis Boraks pada Bakso Daging Sapi C dan D yang di Jual di Daerah Lakarsantri Surabaya Menggunakan Spektrofotometri," Calyptra, vol. 2, pp. 1-10, 2013.

[7] Tubagus dkk, "Identifikasi dan Penetapan Kadar Boraks dalam Bakso Jajanan di Kota Manado," Pharmacon, vol. 2, pp. 142148, 2013.

[8] R. R. Fauziah, "Kajian Keamanan Pangan Bakso dan Cilok yang Beredar di Lingkungan Universitas Jember di Tinjau dari Kandungan Boraks, Formalin dan TPC," Agroteknologi, vol. 8, pp. 68-74, 2014.

[9] Y. Wibisono, Metode Statistik, Yogyakarta: Gajah Mada University Press, 2005.

[10] B. Santoso, "Membangun Gaussian Classifier dalam Mengenali Objek dalam Bentuk Image," Matics, vol. 1, pp. 1-5, 2014.

[11] R. Webb and K. D. Copsey, Statistical Pattern Recognition, 3rd ed., Mathematics and Data Analysis Consultancy Malvern, United Kingdom: John Wiley \& Sons Ltd., 2011.

[12] B. Santoso, "Deteksi Boraks pada Bakso Berbasis Image dengan Menggunakan Tree-Augmented Bayesian Network (TAN)," LP2M UIN Malang, Penelitian Kompetitif Dosen, 2014.

[13] Z. Q. Zhao, "ApLeaf: An Efficient Android-based Plant Leaf Identification System," Neurocomputing, pp. 1-11, 2014.

[14] _, Peraturan Menter Kesehatan Nomor 1168/Menkes/Per/X/1999 tentang Bahan Tambahan Makanan, Jakarta, 1999 